This item was submitted to Loughborough's Research Repository by the author.

Items in Figshare are protected by copyright, with all rights reserved, unless otherwise indicated.

\title{
Dense nanostructured zirconia by two stage conventional/hybrid microwave
} sintering

PLEASE CITE THE PUBLISHED VERSION

PUBLISHER

(c) Elsevier

LICENCE

CC BY-NC-ND 4.0

REPOSITORY RECORD

Binner, J.G.P., Ketharam Annapoorani, Anish Paul, Isabel Santacruz, and Bala Vaidhyanathan. 2008. "Dense Nanostructured Zirconia by Two Stage Conventional/hybrid Microwave Sintering". figshare.

https://hdl.handle.net/2134/3126. 
This item was submitted to Loughborough's Institutional Repository (https://dspace.lboro.ac.uk/) by the author and is made available under the following Creative Commons Licence conditions.

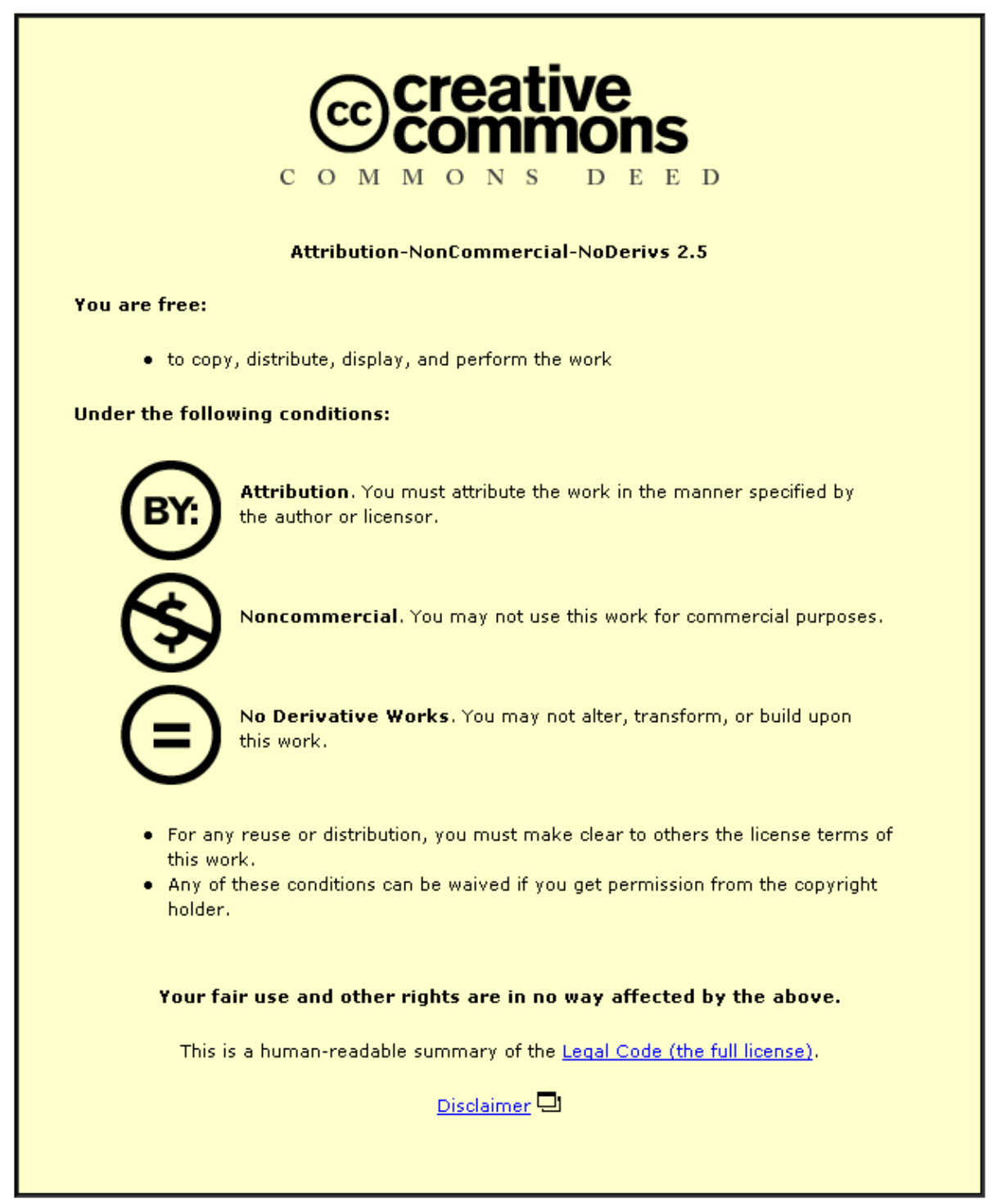

For the full text of this licence, please go to: http://creativecommons.org/licenses/by-nc-nd/2.5/ 


\title{
Dense nanostructured zirconia by two stage conventional/hybrid microwave sintering
}

Jon Binner, Ketharam Annapoorani, Anish Paul, Isabel Santacruz ${ }^{1}$ and Bala Vaidhyanathan IPTME, Loughborough University, UK

\begin{abstract}
The processing of 3 mol\% yttria-partially stabilised zirconia nanopowder into components has been investigated via slip casting low viscosity but high solids content nanosuspensions and subsequent pressureless sintering via one and two stage sintering involving both pure conventional heating and hybrid conventional-microwave heating. Very homogeneous and uniform green bodies with densities up to $\sim 54 \%$ of theoretical could be produced, the major limitation being cracking on drying when the highest solid content suspensions were used. This could be partially overcome via the use of humidity drying. The pressureless sintering of the bodies revealed that the two stage sintering process allows a much finer average grain size to be retained than conventional single stage firing, whilst the use of hybrid heating gave further improvements. Greater than $99 \%$ dense ceramics with average grain sizes of $\sim 65 \mathrm{~nm}$ could be produced from a powder with an average particle size of $\sim 16 \mathrm{~nm}$.
\end{abstract}

Key Words: slip casting, pressureless sintering, nanostructured zirconia

\section{Introduction}

Nanostructured materials have received much attention in recent years; their appeal is their potential to display unusual physical and mechanical properties such as superplasticity in ceramics at elevated temperatures, transparency for usually opaque materials, controlled band gaps in electronic materials, very high magnetoresistance and superparamagnetic properties, and higher hardness and strength in both metals and ceramics [1]. Other benefits include a reduction in the sintering temperatures required, allowing metals and ceramics to be co-fired to a greater extent as well as saving energy, whilst the use of nano-sized components will allow devices to be shrunk significantly in size whilst simultaneously increasing their functionality. However, whilst commercial nanopowders offering these properties have now been produced successfully, sometimes in relatively large quantities, a number of challenges still need to be surmounted if engineering parts are to be manufactured. Whilst 'bottom up' approaches may be the long-term solution, these will not be commercially available for several years - and will require industry to

\footnotetext{
${ }^{1}$ Now with CSIC, Madrid, Spain
} 
completely retool. Therefore there is considerable mileage to be gained by examining what can be achieved practically now using a ‘top down' approach based on existing manufacturing facilities. If components can be produced without loosing the nanostructure, there is the potential to use the materials for mechanical, thermal, magnetic, electric or electronic applications such as tools, wear and structural parts, magnets, capacitors, varistors and electronic substrates [2].

\section{Experimental}

The work presented is based on the processing of 3 mol\% yttria partially stabilised zirconia (3YSZ) nanpowder with an average particle size of $\sim 16 \mathrm{~nm}$, figure 1 . It is produced by MEL Chemicals in the UK as aqueous suspensions of $\sim 5$ vol\% solids content.

The as-received suspension was concentrated to yield nanosuspensions with solids contents up to $\sim 34$ vol\% but with viscosities as low as $\sim 0.2$ Pa s; details of the process are being published elsewhere and a patent application has been submitted and published [3,4,5]. In brief, the process relies on modification of the precursor suspension $\mathrm{pH}$ using solid tetramethylammonium hydroxide, TMAH (Aldrich Chemicals Ltd, Dorset, UK), the latter having the advantage over ammonia solution of not involving the initial further dilution of the precursor nanosuspension, followed by the use as dispersant of either Dispex A40, an ammonium polyacrylate-based dispersant (Allied Colloids, Bradford, UK) or, for better results, a low molecular weight electrostatic surfactant, triammonium citrate, TAC (FSA Laboratory, Loughborough, UK), in both cases combined with the use of multistage ultrasonics to break up any agglomerates present. Of the two concentration methods investigated, evaporation was faster and hence was adopted. These suspensions were subsequently slip cast using standard plaster of paris moulds into either cup $(10 \phi \times 10 \times \sim 1 \mathrm{~mm}$ wall thickness $)$ or rectangular $(40 \times 10 \times 3 \mathrm{~mm})$ green bodies which were subsequently dried at room temperature either with or without control of the humidity during the process.

The green bodies were sintered using both a conventional, single stage and a new two stage sintering approach, originally developed by Chen and Wang [6]; these are illustrated schematically

in figure 2. The conventionally sintered samples were heated at $7^{\circ} \mathrm{C} \min ^{-1}$ to a sintering temperature $\mathrm{T}_{1}$ and held for up to 8 hours and then furnace cooled back to room temperature. The two stage sintered samples were heated at the same $7 \mathrm{~min}^{-1}$ to an initial temperature, $\mathrm{T}_{1}$, but after only 0.1 minutes immediately cooled back down to temperature $\mathrm{T}_{2}$ as rapidly as possible before holding for periods of up to 30 hours. For the single stage sintered samples, $\mathrm{T}_{1}$ was varied from 900 to $1150^{\circ} \mathrm{C}$ whilst for the two stage sintered samples $\mathrm{T}_{1}$ was always $1150^{\circ} \mathrm{C}$ and $\mathrm{T}_{2}$ was varied between 1000 and $1050^{\circ} \mathrm{C}$. Sintering was performed using a hybrid microwave / radiant sintering furnace that 
could be operated in either pure radiant or hybrid microwave/radiant mode. The microwave frequency was $2.45 \mathrm{GHz}$; up to $2 \mathrm{~kW}$ of microwave power was available. In the present work, a fixed level of $600 \mathrm{~W}$ of microwaves was used throughout the sintering cycle for the hybrid heated samples, with the amount of radiant power being varied to yield the desired temperature-time profile. The temperature was measured and controlled using optical thermometry (Orbis Technologies, USA), which previous work has shown is the most accurate method [7]. Corroborative temperature distribution measurements were performed using a thermal imaging camera (FLIR Systems Thermovision ${ }^{\circledR}$ A40, USA).

After sintering, the samples were characterized in terms of their densities, using the Archimedes technique in deionised water, and their grain size, after gold coating, using a field emission gun scanning electron microscope (FEG-SEM). For the latter, the procedure followed that laid out in British Standards [8].

\section{Results and Discussions}

The rheology of the optimised precursor nanosuspension is shown in figure 3. It can be seen how the viscosity of the as-received suspension increased very rapidly with concentration, exceeding 1 Pa s by 15 vol\%. Whilst the use of Dispex A40, together with appropriate exposure to ultrasound to destroy any agglomerates present, allowed much higher solids contents to be achieved whilst retaining a low viscosity, it may be seen the short molecule TAC was even more successful. Up to $\sim 34$ vol\% suspensions could be produced whilst retaining the viscosity below $\sim 0.3$ Pa s.

When these nanosuspensions were slip cast, very homogeneous green bodies were formed, figure 4, however cracking was found to be a major problem for the higher solid content suspensions. For conventional drying, the maximum solids content that could be cast without cracking was 12 vol\%, however when humidity drying was used, and optimized, suspensions with solids contents of up to 20 vol\% could be slip cast without cracks being observed in the dried bodies. These higher solids contents not only allowed higher green density bodies to be achieved, up to $\sim 54 \%$ of theoretical, but also resulted in a finer pore structure, figure 5 , that, in turn, resulted in higher sintered densities for the same sintering conditions.

The average grain size of the sintered nanostructured samples is plotted as a function of sample density in figure 6, whilst representative micrographs of the structures at three different points on the sintering curves, labelled a, b and c, are shown in figure 7. Two results are immediately observable from figure 7. The first is that the use of hybrid heating has consistently resulted in a 
finer average grain size for a given final density and the second is that the use of two stage sintering does indeed seem to result in the ability to retain a very fine grain size, whilst achieving effectively full densification.

With radiant heating, there was a steady increase in grain size up to around $90-95 \%$ of full density when there was a sharp increase in grain size. This fits with the closing of the porosity, when grain growth generally becomes significant. The use of two stage sintering, however, clearly reduced grain growth whilst allowing densification to continue occur, confirming the results proposed by Chen et al. [6] using nano $\mathrm{Y}_{2} \mathrm{O}_{3}$ powder. Their argument was that the suppression of the final-stage grain growth was achieved by exploiting the difference in kinetics between grain-boundary diffusion and grain-boundary migration and that the particle network became 'frozen' during the second sintering stage. Like them, it was observed that to succeed in two-stage sintering a density $\geq 75 \%$ of theoretical had to be obtained during the first stage. It is believed that the benefit arising from this level of densification was actually related to the pores, which became subcritical and so unstable against shrinkage, rather than the density value itself.

The use of hybrid heating can be seen to have resulted in a much finer average grain size at all densities. Although recent results from Loughborough have now confirmed the existence of the socalled 'microwave effect' during ceramic sintering [9], it is believed that the major effect influencing these results is that a much faster heating rate was used. Due to the volumetric nature of the hybrid heating, $20^{\circ} \mathrm{C} \mathrm{min}{ }^{-1}$ could be used without risking any damage to the samples from thermal stresses, whilst the radiant heating was limited to only $7^{\circ} \mathrm{C} \mathrm{min}{ }^{-1}$. At higher heating rates the bodies were found to crack as a result of thermal expansion mismatch between the surface and centre of the bodies due to the low thermal conductivity in these materials. Since, as indicated by Chen et al. [6], the bulk of the grain growth that occurs during two stage sintering is during the initial heating to $T_{1}$, the faster this stage can occur, the smaller the amount of grain growth overall. As for the radiantly heated samples, the rapid increase in grain growth began at densities of 9095\%; achieving full density resulted in average grain sizes $\geq 160 \mathrm{~nm}$. However, the combination of hybrid heating with the two stage sintering technique clearly resulted in the ability to retain a final grain size in the range $60-80 \mathrm{~nm}$ whilst achieving densities in excess of 99\%. Figure 8 illustrates the homogeneity that was achieved across the entirety of a sample. The density was $\sim 99.5 \%$ of theoretical and the average grain size was $64 \mathrm{~nm}$.

In the original work of Chen and co-workers [6], figure 10, the curve representing the second stage of sintering was horizontal; it was this that gave rise to their claim that the microstructure was 
'frozen' during the second stage of sintering. In the current work it can be seen that it is curved in a similar manner to the single stage sintering data but with a significant increase in average grain size occurring at densities above about $97 \%$ of theoretical. This suggests that the operative mechanism during two stage sintering may be essentially the same as during conventional sintering but the densification curve is pushed to the right by the samples effectively having a much higher green density than would be normal for ceramic sintering. Further work is needed to clarify this situation, since, if the present work is correct then this casts doubt on the mechanism proposed by Chen et al.

\section{Conclusions}

It has been possible to concentrate commercial, low solids content aqueous nanosuspensions consisting of $\sim 16 \mathrm{~nm} 3 Y$ SZ powder particles up to $\sim 32.5$ vol\% solids content whilst retaining a viscosity as low as 0.2 Pa s using a new process; a patent application has been submitted. These nanosuspensions have subsequently been slip cast using standard plaster of paris moulds to yield green bodies that are very uniform and homogeneous. Significant problems with cracking on drying for the samples made from the nanosuspensions with solids contents greater than $\sim 12$ vol\% have been at least partially overcome by the use of humidity drying. This allowed suspensions with solids contents up to 20 vol\% to be slip cast without any evidence of cracking; these yielded green bodies with densities of $\sim 54 \%$ of theoretical.

The green bodies could be sintered to $>99 \%$ of theoretical using a two stage sintering technique whilst retaining a final average grain size of $<100 \mathrm{~nm}$. When a hybrid microwave-conventional approach was used, the resulting average grain size was finer; the best sample to date had a value of just $64 \mathrm{~nm}$ whilst being $~ 99.5 \%$ dense. It is believed that the primary advantage offered by the hybrid heating approach is the ability to use a much faster initial heating rate, 20 versus just $7^{\circ} \mathrm{C} \mathrm{min}{ }^{-1}$, since the bulk of the grain growth observed using this approach occurs during heating to the first sintering temperature, known as $T_{1}$. The nanostructure was also very uniform throughout the sample.

Unlike the work of Chen et al [6], who developed the two stage sintering process, the nanostructure did not remain 'frozen' during sintering at $\mathrm{T}_{2}$. Instead, a relatively small amount of grain coarsening was observed at densities above about $97 \%$ of theoretical. This suggests that the mechanisms taking place during the second stage of the sintering process are similar to those occurring conventionally but shifted to higher densities. Further work is clearly needed and is underway at Loughborough. 


\section{References}

1. M.Mayo, "Processing of nanocrystalline ceramics from ultrafine particles," Int. Mater. Rev., 41 [85] 1743-2804 (1996).

2. Groza JR, Int. J. Powder Met. 35 [7] 59 (1999).

3. Santacruz MI, Binner JGP \& Annapoorani K, "Preparation of high solids content nano zirconia suspensions - Part I”, submitted to J Am Ceram. Soc.

4. Santacruz MI, Binner JGP \& Annapoorani K, "Preparation of high solids content nano zirconia suspensions - Part II”, submitted to J Am Ceram. Soc.

5. Binner JGP, Santacruz MI \& Annapoorani K, “Aqueous nanosuspensions”, International patent application Publ. No. WO 2006/136780 A2, Publ. Date 28/12/06.

6. Chen I \& Wang X-H, "Sintering dense nanocrystalline ceramics without final-stage grain growth”, Nature 404 168-171 (2000).

7. Binner JGP, Vaidhyanathan B \& Wang J, “A comparative study of temperature measurements during microwave processing”, Proc. of the $9^{\text {th }}$ Int. Conf. on Microwave and High Frequency Heating, Loughborough, UK, 477-480 (2003).

8. British Standards, “Advanced Technical Ceramics - Monolithic Ceramics - General Textural Properties” Part 3, p 10 BS EN 623-3 (2001).

9. Wang J, Binner J, Vaidhyanathan B, Joomun N, Kilner J, Dimitrakis G \& Cross TE, "Evidence for the microwave effect during hybrid sintering”, J Am Ceram Soc. 89 [6] 1977-1984 (2006). 